\title{
Effects of Chemical Modification of Liquid Crystalline Polymer on the Rheological, Morphological, and Mechanical Properties of Nylon 6/Liquid Crystalline Polymer Blends
}

\author{
Seung Hyun Kim, Gi Dae CHOI, and Won Ho Jo* \\ Department of Fiber and Polymer Science, Seoul National University, \\ Seoul 151-742, Korea
}

(Received January 5, 1995)

\begin{abstract}
A liquid crystalline polymer (LCP) is chemically modified with maleic anhydride, and then its effects on the rheological, morphological, and mechanical properties of nylon 6/LCP blends are investigated. The complex and shear viscosities of nylon 6/modified LCP blends are higher than those of nylon 6/unmodified LCP blends over the entire frequency and shear rate range examined. In the plots of $\log G^{\prime}$ versus $\log G^{\prime \prime}$, the modified LCP blends show more elastic properties as compared with the unmodified blends. The morphology of fracture surface shows that the domain size and its distribution of the modified LCP blends are finer and more uniform than those for the unmodified ones. The mechanical properties of the modified LCP blends are better than those of the unmodified LCP ones. These results are attributed to the formation of in situ graft copolymer resulting from the reaction between maleic anhydride grafted onto LCP and the terminal amine group of nylon 6 .
\end{abstract}

KEY WORDS Liquid Crystalline Polymer / Nylon 6 / Polymer Blend / In Situ Graft Copolymer / Morphology / Rheological Properties / Mechanical Properties /

Polymer blends containing liquid crystalline polymers (LCPs) have attracted much attentions due to the potential to generate in situ reinforced composites for the last decade. ${ }^{1-8}$ When the LCPs are incorporated into isotropic thermoplastic materials, they can easily develop a fibrillar morphology with a high degree of orientation within the thermoplastic matrix under proper processing conditions, leading to so-called in situ reinforced composites. ${ }^{9-13}$ Furthermore, even relatively small amount of LCP can induce the reduction of the melt viscosity of the blends and thus make the processing easier. ${ }^{1,14-16}$ However, in the same manner as most polymer pairs, the majority of the thermoplastics are incompatible with the LCPs. This incompatibility gives rise to the poor adhesion between matrix polymer and

\footnotetext{
* To whom correspondence should be addressed.
}

reinforcing LCPs and poor dispersion of LCP domains within the thermoplastic matrix, which leads to a lower reinforcing effect than expected from the simple additive rule for both strength and modulus of the blends, although the blends sometimes exhibited significant improvement in modulus. These observed phenomena of the LCP blends are attributed to the incompatibility between the blend components.

Among the various methods compatibilizing the polymer blends a polymeric compatibilizer can be widely used to improve the compatibility of polymer blends. ${ }^{17}$ This compatibilization may be classified into two different types according to the addition method of the polymeric compatibilizers. One is to introduce separately a small amount of block or graft copolymers that will interact with both phases 


\section{Modification of LCP}

LCP

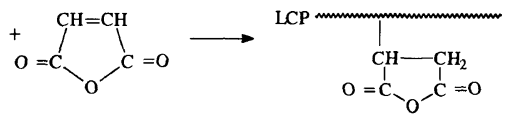

Blending of Modified LCP with Nylon 6

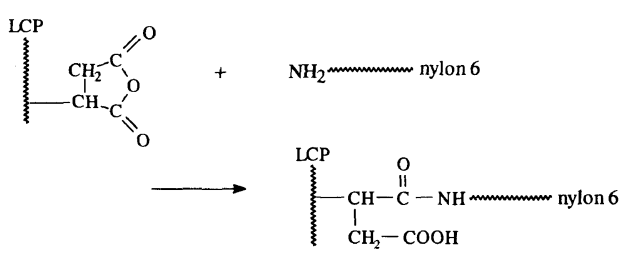

Figure 1. Schematic representation of the reactions expected to occur in this system.

chemically or physically. The choice of a block or graft copolymer as a compatibilizer must be based on the miscibility and/or reactivity of block or graft segments with at least one of the blend components. Another method is reactive compatibilization, which is to use suitably functionalized polymers capable of the enhanced specific interaction and/or chemical reactions and thus to induce in situ block or graft copolymers during blending. This method, compared to the former, has economic merit in that it is not required to synthesize the block or graft copolymers before mixing.

In this work, a copolymer of poly ( $p$-hydroxy benzoic acid) with poly(ethylene terephthalate) and nylon 6 are chosen as a reinforcing LCP component and a thermoplastic matrix, respectively. The LCP is then functionalized with maleic anhydride, since it is well known that maleic anhydride readily react with amine groups of nylon 6 to form in situ graft copolymers during melt blending. Figure 1 shows this reaction scheme occurring in the system. It is expected that the in situ graft copolymers preferentially locate at the interface between LCP and nylon 6 phases, reduce the interfacial tension between the two phases to render a finer dispersion of dispersed domain and improve the interfacial adhesion. Therefore, it is of our primary object to investigate the effect of the functionalized LCP with maleic anhydride on the rheological, morphological, and mechanical properties of nylon 6/LCP blends.

\section{EXPERIMENTAL}

\section{Materials}

The thermoplastic material used is nylon 6 supplied by Kolon Inc. The LCP used in this work is a random copolyester of $40 \mathrm{~mol} \%$ poly(ethylene terephthalate) (PET) and 60 mol\% poly( $p$-hydroxy benzoic acid) (PHB), commercially known as RODRUN LC-3000 (from Unitika Co.). All materials were used without further purification.

\section{Chemical Modification of LCP}

The LCPs are usually not soluble in common solvents since they have the rigid chain backbones. Consequently, the chemical modification of LCP with maleic anhydride is carried out in a heterogeneous reaction system. In such a system the diffusion of maleic anhydride into the internal structures of the polymer controls the overall reaction. One way of facilitating diffusion is to open up the physical structure of the polymer by swelling with the preferentially interacting solvents. In order to find the best swelling solvent, we follow the following procedure. First, the solubility parameter of LCP is calculated by group contribution method. ${ }^{18}$ Secondly, the solvents having solubility parameter close to that of LCP are chosen from the list of solubility parameter for various solvents. Third, the LCP is swollen with the solvents chosen alone, and finally the solvents showing the largest swelling is selected. As shown in Table I, the dimethyl sulfoxide (DMSO) showed the highest swelling, and thus it was chosen as the most suitable swelling agent for the LCP. Therefore, in this work, LCP was swollen with DMSO at $80^{\circ} \mathrm{C}$ for $3 \mathrm{~h}$ before the reaction with maleic anhydride. The swollen LCP was then reacted with maleic anhydride in xylene as a solvent. The weight 
Table I. Solubility parameters and swelling properties for various solvents

\begin{tabular}{|c|c|c|}
\hline \multirow{2}{*}{ Solvents } & $\begin{array}{l}\text { Solubility } \\
\text { parameter }\end{array}$ & $\begin{array}{c}\text { Weight } \\
\text { gain }^{\text {a }}\end{array}$ \\
\hline & $\left(\mathrm{cal} \mathrm{cm}^{-3}\right)^{1 / 2}$ & $\%$ \\
\hline Dioxane & 10.0 & 2.18 \\
\hline Nitrobenzene & 10.0 & 5.37 \\
\hline$m$-Cresol & 10.2 & 10.40 \\
\hline Acrylonitrile & 11.4 & 8.34 \\
\hline$n$-Butyl alcohol & 12.0 & 16.30 \\
\hline DMSO & 12.0 & 17.89 \\
\hline Benzyl alcohol & 12.0 & 17.53 \\
\hline Ethyl alcohol & 12.7 & 13.66 \\
\hline Propylene carbonate & 13.3 & 10.03 \\
\hline Methyl alcohol & 14.5 & 4.91 \\
\hline DMSO & 12.0 & $18.86^{\mathrm{b}}$ \\
\hline
\end{tabular}

${ }^{a}$ Determined at room temperature for $1 \mathrm{~h} .{ }^{\mathbf{b}}$ Determined at $80^{\circ} \mathrm{C}$ for $3 \mathrm{~h}$.

ratio of maleic anhydride to $\mathrm{LCP}$ was $1 / 1$. The reaction was carried out at $140^{\circ} \mathrm{C}$ for $5 \mathrm{~h}$ under nitrogen atmosphere. Then the chemically modified LCP was dried under vacuum at $80^{\circ} \mathrm{C}$ for 2 days.

\section{Blend Preparation}

Chemically modified and unmodified LCPs were melt-blended with nylon 6 at $250^{\circ} \mathrm{C}$ for 4 min and injection-molded using the Mini-Max injection molder (Model CS-183 MMX, Custom Scientific Instrument, Inc.). To prevent the thermal degradation of the blend components, $0.1 \mathrm{wt} \%$ Irganox (Irganox 1010, CibaGeigy Co.) as an antioxidant was added to the blends.

\section{Rheological Measurements}

The rheological properties of the blends and their components were determined on a Rheometrics mechanical spectrometer (RMS 800 ). Both steady shear and dynamic oscillatory properties were measured using the cone and plate geometry of the diameter of $25 \mathrm{~mm}$ and the cone angle of 0.1 radian. A strain of $10 \%$ was used for all testing materials.

\section{Morphological Analysis}

The morphology of the blends was observed by means of scanning electron microscope (XL-SEM, Philips Co.) with an accelerating voltage of $25 \mathrm{kV}$. All the samples were cryogenically fractured, and the fracture surfaces were then coated with gold.

\section{Tensile Testing}

The tensile properties of the blends and their components were measured with the dumbbell type specimens on an Instron mechanical tester (model 4204). All tests were performed at a constant cross-head speed of $5 \mathrm{~mm} \mathrm{~min}^{-1}$. All mechanical properties were reported by averaging at least eight test results for each composition.

\section{RESULTS AND DISCUSSION}

\section{Rheological Properties}

For in situ composites containing LCPs to exhibit the better resultant properties, it is necessary to obtain the fibrillar structure of the LCP domains within the thermoplastic matrix. The formation of in situ LCP fibrillar reinforcement is not always easy to achieve since it depends upon many factors such as the viscosity ratio, composition of LCP, interfacial tension, magnitude and type of flow field, etc. Therefore, the effects of such factors must be taken into account before LCPs are blended with the thermoplastic materials.

Figure 2 shows the changes for the complex viscosities of nylon 6 and LCP with temperature during cooling from $290^{\circ} \mathrm{C}$. This figure provides two important information: First, there exists an overlapped processing temperature range between nylon 6 and LCP, i.e., the temperature range higher than $\sim 210^{\circ} \mathrm{C}$ below which the complex viscosities begin to increase abruptly. Second, the viscosities of LCP are lower than those of nylon 6 over the entire temperature range measured. The development of the fibrillar structure of LCP in the matrix polymer requires the condition that the 


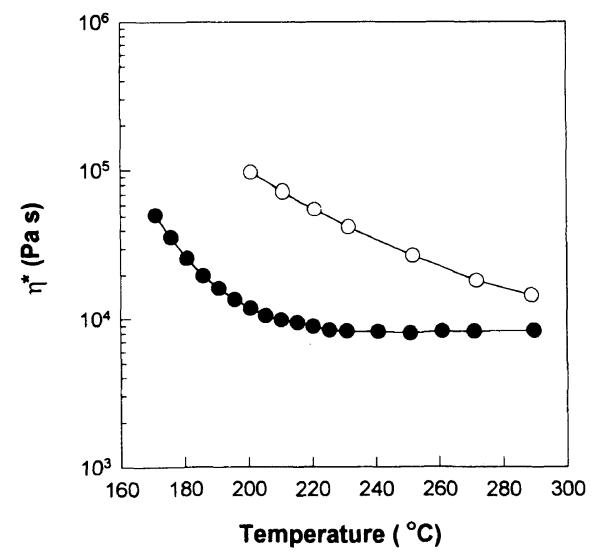

Figure 2. Complex viscosity of component polymers as a function of temperature during cooling from $290^{\circ} \mathrm{C}$ at $6.28 \mathrm{rad} \mathrm{s}^{-1}: \mathrm{O}$, nylon 6; $\mathrm{O}, \mathrm{LCP}$.

viscosity of LCP should be lower than that of the matrix, because the droplets of dispersed phase will elongate by shear stress when the viscosity of dispersed phase is lower than the continuous one $\left(\eta_{\mathrm{d}} / \eta_{\mathrm{m}}<1\right)$. In the opposite case where the viscosity of dispersed phase is higher than the continuous one $\left(\eta_{\mathrm{d}} / \eta_{\mathrm{m}}>1\right)$, it is difficult to deform the suspended droplets except the case by very high stresses. ${ }^{19}$ Therefore, in this system it is expected that the LCP phases can be easily elongated into the fibrils in the nylon 6 matrix during melt blending.

Figure 3(a) shows the frequency dependence of the complex viscosities of nylon $6, \mathrm{LCP}$, and their blends at $250^{\circ} \mathrm{C}$. It can be seen that the viscosities of nylon 6 are 10-100 times higher than those of LCP over the frequency range examined. The viscosities of blends decrease with increasing the LCP content. Especially, the viscosity decreases abruptly at lower LCP contents as is typical for the blends containing LCP. Moreover, the viscosities of nylon 6/LCP $(5 / 5)$ blend are even lower than those of the individual components over the entire frequency range. This behavior can be attributed to the incompatibility between LCP and nylon 6 and the lubricant effect by slippage of LCP in the nylon 6 matrix. Similar results are observed for nylon 6/modified LCP blends in
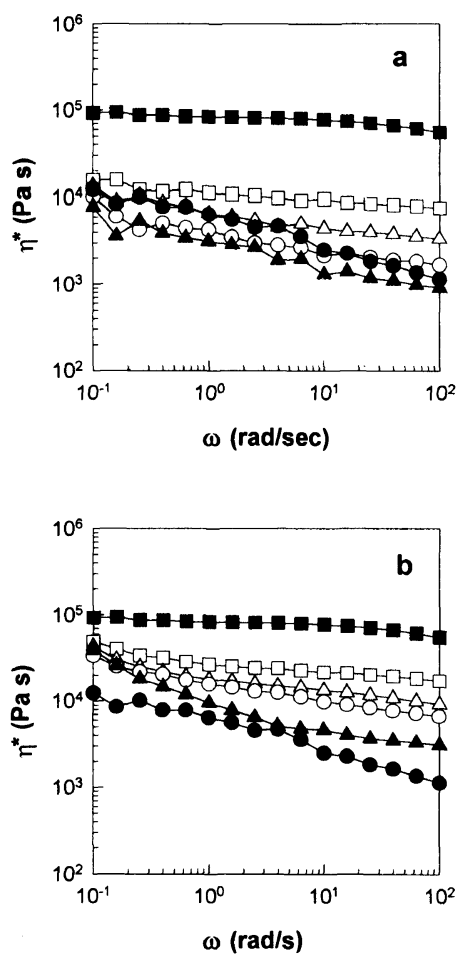

Figure 3. Complex viscosity $v s$. frequency for nylon 6/unmodified LCP blends (a) and nylon 6/modified LCP blends (b) at $250^{\circ} \mathrm{C}$ : $\square$, nylon $6 ; \square, 9 / 1 ; \triangle, 8 / 2 ; \bigcirc, 7.3$; $\Delta, 5 / 5 ;$, LCP.

Figure 3(b). However, the minimum viscosity is not observed for the modified blend systems.

The difference of rheological behavior between unmodified and modified LCP blends is clearly shown in Figure 4. The complex viscosities of the modified LCP blends are higher than those of the unmodified blends over entire compositions. This phenomenon may be due to in situ graft copolymers which are formed during melt blending through the reaction between maleic anhydride group attached to LCP and the amine end group of nylon 6 . In other words, the formation of in situ graft copolymer increases the molecular weight of the blends, which results in the increase in the complex viscosities. This provides an indirect evidence that the $\mathrm{LCP}-g$ nylon 6 copolymer is formed by the chemical reaction during melt blending, as shown in 

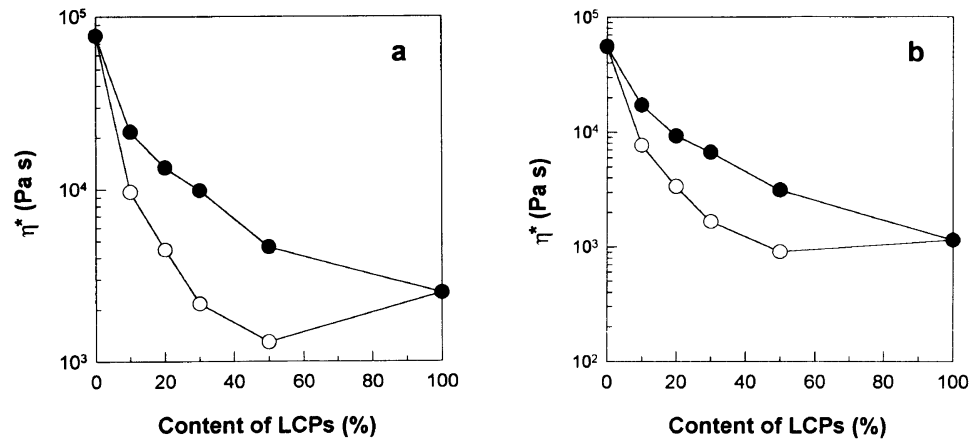

Figure 4. Complex viscosity vs. content of LCP for nylon 6/LCP blends at a frequency of $10 \mathrm{rads}^{-1}$ (a) and $100 \mathrm{rad} \mathrm{s}^{-1}$ (b). Open and filled symbols represent the unmodified LCP and modified LCP blends, respectively.
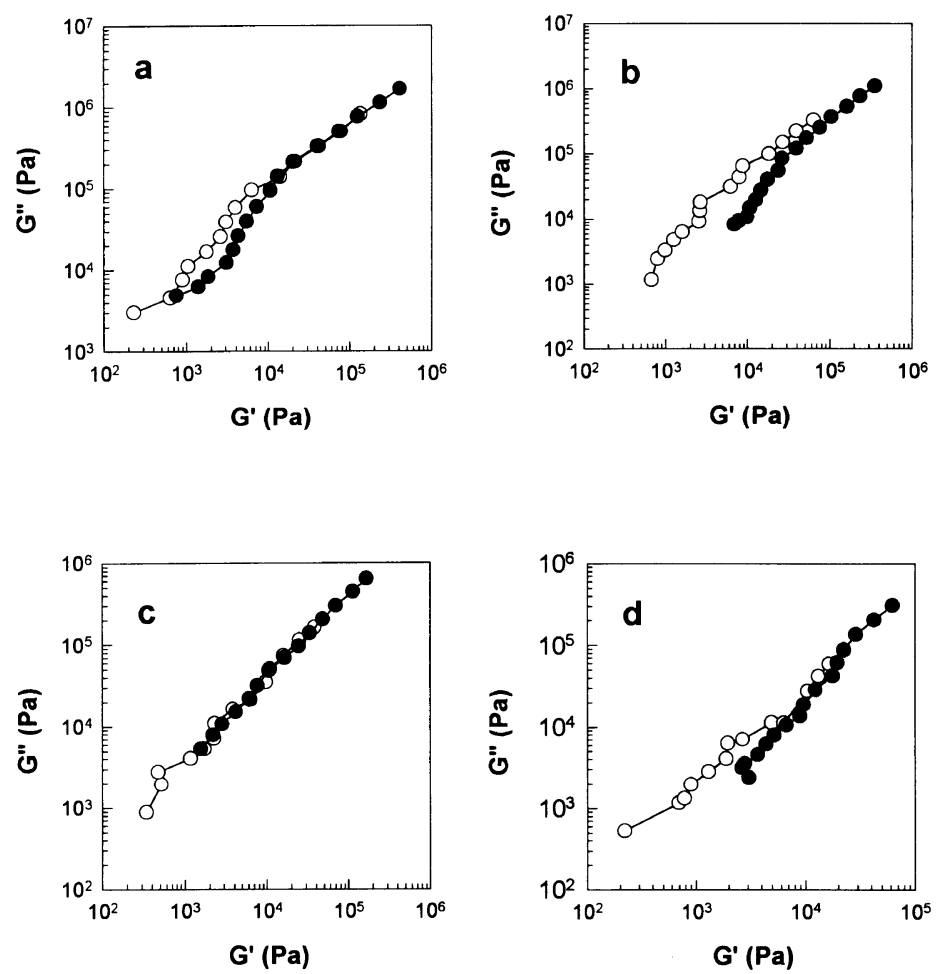

Figure 5. The $\log G^{\prime}$ versus $\log G^{\prime \prime}$ plots for nylon 6/LCP blends: a, 9/1; b, 8/2; c, 7/3; d, 5/5. Open and filled symbols represent the unmodified and modified LCP blends, respectively.

Figure 1.

Figure 5 shows the log-log plot of loss modulus against storage modulus $\left(\log G^{\prime}\right.$ vs. $\log G^{\prime \prime}$ ) for nylon 6/LCP blends. Several investigators, Han et al. ${ }^{20,21}$ and others, ${ }^{22}$ showed the usefulness of this plot for rheological analysis of various polymer systems. Han et al..$^{20,21}$ reported that such plots are very slightly affected by temperature and molecular weight, but strongly dependent upon the 

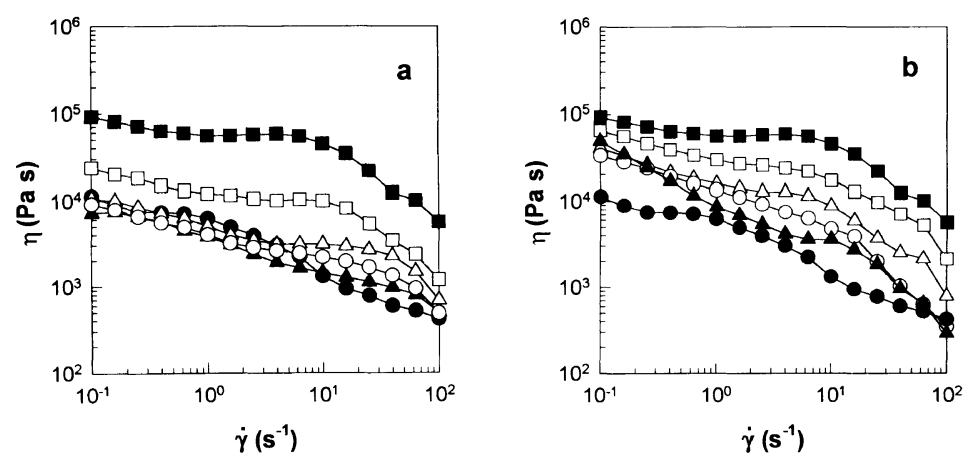

Figure 6. Shear viscosity vs. shear rate for nylon 6/unmodified LCP blends (a) and nylon 6/modified LCP blends (b): $\square$, nylon $6 ; \square, 9 / 1 ; \triangle, 8 / 2 ; \bigcirc, 7 / 3 ; \triangle, 5 / 5 ; \bigcirc$, LCP.

molecular weight distribution (MWD) and the side-chain branching. Independently, Harrell and Nakajima ${ }^{22}$ also demonstrated the effectiveness of the plot (which they call the modified Cole-Cole plot) for the characterization of molecular weight distribution, side-chain branching, and morphological structure of polymers. Especially, they showed that the change in MWD by the side-chain branching of model samples were readily detected as systematic variation in shape and displacement of the plots. As shown in Figure 5, the curves of the modified blends shift toward the righthand side as compared with those of the unmodified LCP blends at the same composition. This indicates that the modified LCP blends have more elastic properties than the unmodified ones, which probably results from broadening of MWD due to the formation of the graft copolymers during melt mixing. Therefore, this behavior may provide another indirect evidence of the formation in situ graft copolymer by the chemical reaction between maleic anhydride group in LCP and the terminal amine group in nylon 6. It has been known that the rheological behavior of immiscible blends strongly depends on the morphology. ${ }^{23}$ Especially, the deformability of the dispersed phases greatly influences their bulk rheological properties. In Figure 5, a comparison between modified and unmodified blends has been made for the data obtained at the same composition and under the same processing condition. Therefore it is assumed that only the change of molecular structure affects the rheological behavior, because the degree of deformation of the dispersed phase in the matrix phase is the almost same, although there exists the change of domain size of the dispersed phase due to the reduction of interfacial tension. The effect of interfacial tension on morphology will be discussed later.

The changes in viscosity under the steady shear test are shown in Figure 6. As in the case of the dynamic tests, the steady shear viscosities decrease with increasing the LCP content. When the modified LCP blends (Figure 6(a)) are compared with the unmodified LCP blends (Figure 6(b)), it reveals that the shear yielding behavior is more clearly observed at lower shear rates for the modified LCP blends. This is probably a consequence of the formation of graft copolymers during melt mixing, since it is known that the shear yielding behavior at lower shear rates is attributed to the side-chain branching. ${ }^{22,24}$

\section{Morphological Properties}

Figure 7 shows the fracture surfaces of nylon 6/unmodified LCP and nylon 6/modified LCP blends. This figure shows only the core regions of specimens in order to observe the effects of the chemical modification of LCP on the morphological structure. In this region the 
Properties of Nylon 6/LCP Blends

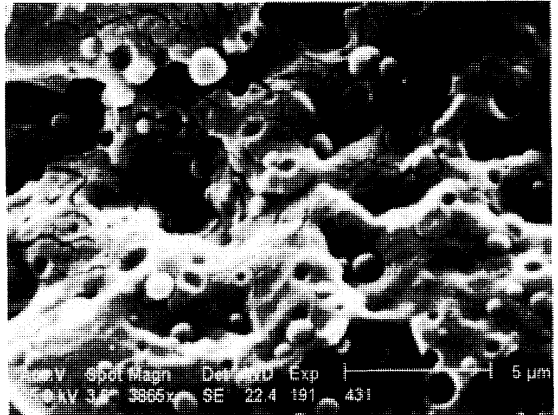

a-1

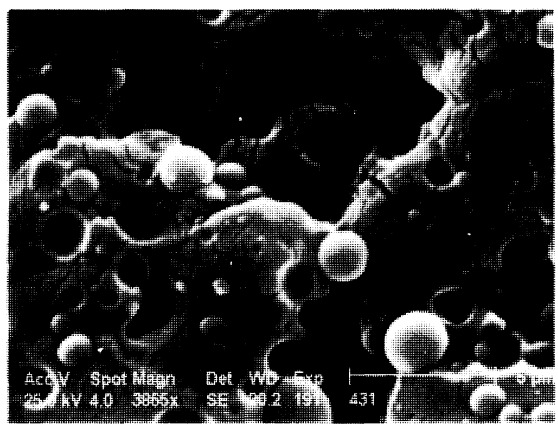

b-1

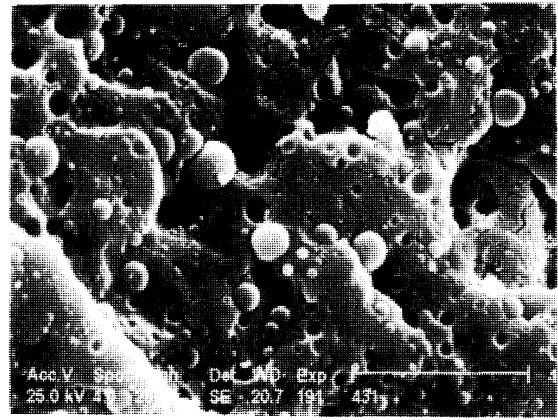

c-1

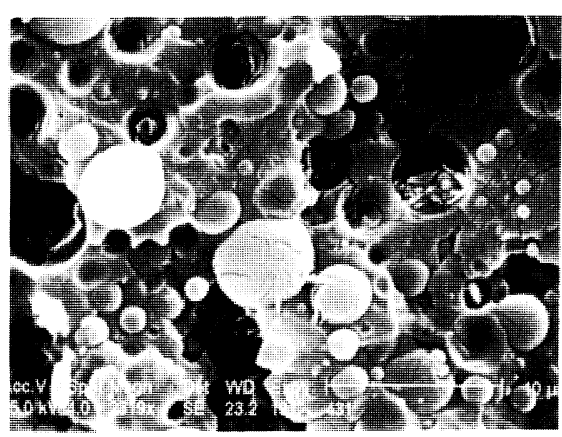

d-1

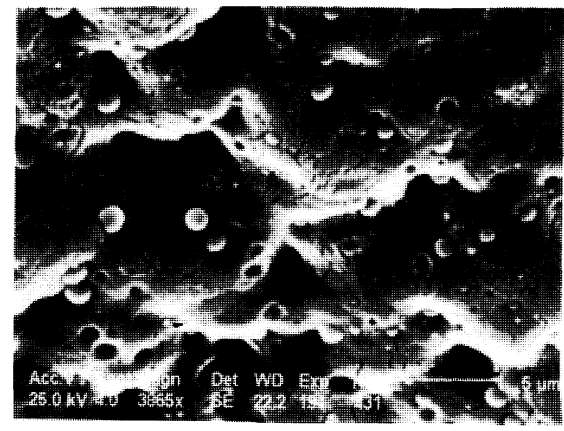

a-2

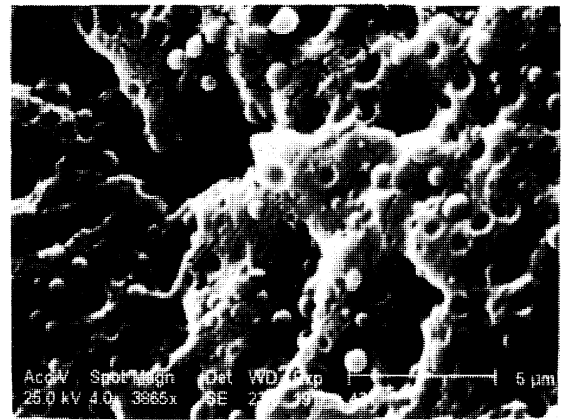

b-2

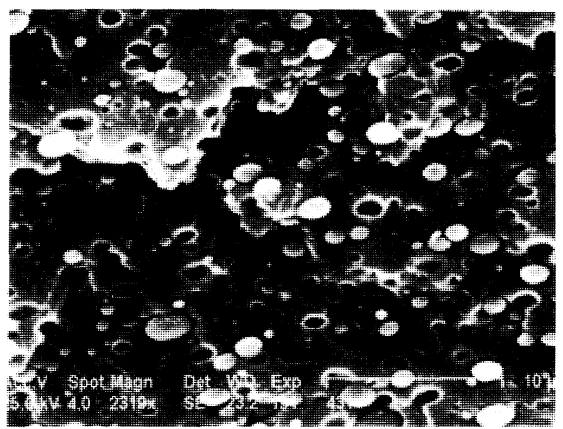

c-2

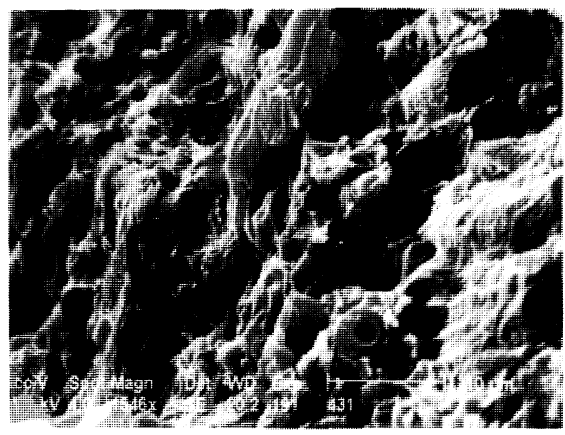

d-2

Figure 7. Scanning electron micrographs of nylon $6 /$ LCP blends: a, $9 / 1 ; b, 8 / 2 ; c, 7 / 3 ; d, 5 / 5$ blends. The number 1 and 2 behind $\mathrm{a}-\mathrm{d}$ denote unmodified and modified LCP blends, respectively. 
LCP domains are dispersed as either spherical or ellipsoidal shapes because they are affected mainly by shear flow. On the other hand, in the skin region where the elongational flow dominates, the LCP domains become highly elongated and oriented (not shown here). When the fracture surfaces of nylon $6 /$ modified LCP blends (Figure 7(a-d-2)) are compared with those of nylon 6/unmodified LCP blends (Figure 7(a-d-1)), it reveals that the domain size and its distribution of modified blends are finer and more uniform than those of unmodified ones. This suggests that in situ graft copolymers are formed by the reaction of maleic anhydride in LCP with terminal amine groups in nylon 6 and that the graft copolymers are preferentially located at the interface between nylon 6 and LCP phases. Consequently, in situ graft copolymers reduce the interfacial tension between two incompatible polymers. Especially, for the modified LCP $5 / 5$ ) blends the LCP domains are not clearly observed, and the nylon matrix shows a rough fracture surface which indicates a considerable improvement of the interfacial adhesion between the two phases.

\section{Mechanical Properties}

Very often the mechanical properties of incompatible polymer blends are poor and do not obey the simple additive rule. This behavior usually results from the poor interfacial adhesion between two phases of the blends that may provide a multiplicity of defects for early failure. In such cases, significant improvements in the mechanical properties can be achieved by compatibilization between two polymers.

Figure 8 shows the mechanical properties of nylon 6/unmodified LCP and nylon 6/modified LCP blends as a function of the LCP content. For the unmodified LCP blends, the maximum stress shows a strong negative deviation from the simple additive rule. Generally, this behavior arises from the poor interfacial adhesion between two phases of incompatible polymer blends. On the other hand, for the
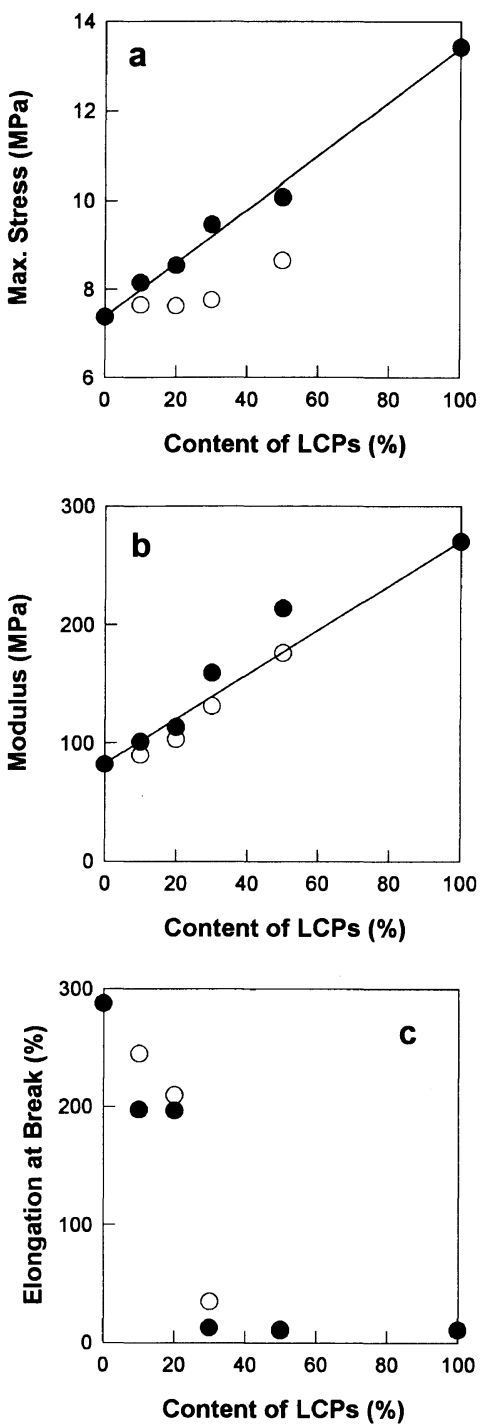

Figure 8. Mechanical properties of nylon 6/LCP blends as a function of the LCP content. Open and filled symbols represent the unmodified and modified LCP blends, respectively.

modified blends the maximum stresses not only are higher than those for the unmodified ones but also follow the simple additive rule (Figure 8(a)). This result may be due to the increased interfacial adhesion between nylon 6 and LCP phases resulting from in situ graft copolymers. In other words, it seems that in situ graft copolymers preferentially locate at interface, 
improve the adhesion between two phases, help the stress transfer through the interface and thus make blends follow the simple additive rule. Figure $8(\mathrm{~b})$ shows a comparison of the moduli of unmodified LCP blends with the modified ones. It is generally observed that blends containing LCPs exhibit the increased modulus due to the contribution of their rigid chain backbones. Moreover, the LCP in the thermoplastic matrix becomes easily elongated along the flow direction, and thus serves as a reinforcing additive. The moduli of nylon 6/modified LCP blends are greater than those of unmodified blends and show a positive deviation from the simple additive rule, while the moduli of nylon 6/unmodified LCP blends increase with the LCP content and follow the simple additive rule. This phenomenon may also come from the increased compatibility by in situ graft copolymer. Figure 8(c) shows the elongation at break of the unmodified and modified LCP blends. As can be seen, both blends exhibit two different failure mechanism according to the LCP content. At lower compositions of LCP, the blends show the ductile behavior mainly governed by the ductile nylon 6 matrix. However, at above $30 \mathrm{wt} \%$ of LCP the blends show the brittle behavior mainly dominated by LCP. In any case, the difference of the elongation at break between the unmodified and modified LCP blends is small.

\section{CONCLUSIONS}

The properties of nylon 6/LCP blends are examined. Especially a LCP is chemically modified with maleic anhydride, and then its effects on the resultant properties of nylon 6/LCP blends are investigated. The modified LCP blends show the different rheological properties. More specificially, the modified blends show more elastic behavior as compared to the unmodified blends. From SEM micrographs, it is observed that the domain sizes and their distributions of nylon 6/modified LCP blends are finer and more uniform than those of the unmodified LCP blends. The maximum stress and modulus of modified blends are significantly improved as compared with those of unmodified blends: the maximum stress and modulus of modified blends follow the simple additive rule and a positive deviation, respectively, whereas the maximum stress and modulus of unmodified ones follow a strong negative deviation and the simple additive rule, respectively. From above results, it is concluded that maleic anhydrides grafted onto LCP react with the amine end groups in nylon 6 leading to the formation of in situ graft copolymer and then the graft copolymers may play a proper role as a good interfacial agent for nylon 6/LCP blends.

Acknowledgment. The authors thank the Ministry of Trade, Industry and Energy of the Republic of Korea and Kolon Industry Inc. for their financial support (1992).

\section{REFERENCES}

1. A. Siegmann, A. Dagan, and S. Kenig, Polymer, 26, 1325 (1985).

2. G. Kiss, Polym. Eng. Sci., 27, 410 (1987).

3. A. M. Sukhadia, D. S. Done, and D. G. Baird, Polym. Eng. Sci., 30, 519 (1990).

4. K. G. Blizard, C. Federici, O. Federico, and L. L. Chapoy, Polym. Eng. Sci., 30, 1442 (1990).

5. J. F. Croteau and G. V. Laivins, J. Appl. Polym. Sci., 39, 2377 (1990).

6. D. Beery, S. Kenig, and A. Siegmann, Polym. Eng. Sci., 31, 459 (1991).

7. T. Sun, D. G. Biard, H. H. Huang, D. S. Done, and G. L. Wilkes, J. Comp. Mater., 25, 788 (1991).

8. A. M. Sukhadia, A. Datta, and D. G. Baird, Int. Polym. Proc., 7, 218 (1992).

9. A. K. Mithal, A. Tayebi, and C. H. Lin, Polym. Eng. Sci., 31, 1533 (1991).

10. M. Evstatiev and S. Fakirov, Polymer, 33, 877 (1992).

11. A. Ajji, T. Brisson, and Y. Qu, J. Polym. Sci., B, Polym. Phys. Ed., 30, 505 (1992).

12. G. Grevecoeur and G. Groeninckx, Polym. Comp., 13, 244 (1992).

13. J. He, W. Bu, H. Zhang, D. Xie, and X. Xu, Int. Polym. Proc., 8, 129 (1993).

14. F. P. La Mantia, A. Nalenza, M. Paci, and P. L. Magagnini, Rheol. Acta, 28, 417 (1989).

15. F. P. La Mantia, A. Nalenza, M. Paci, and P. L. 
Magagnini, Polym. Eng. Sci., 30, 7 (1990).

16. N. R. Nobile, D. Acierno, L. Incarnato, E. Amendola, and L. Nicolais, J. Appl. Polym. Sci., 41, 2723 (1990).

17. M. Xanthos, Polym. Eng. Sci., 28, 1392 (1988).

18. D. W. Van Krevelen, "Properties of Polymers," Elsevier Scientific Publishing, Amsterdam, 1990.

19. K. Min, J. L. White, and J. F. Fellers, Polym. Eng. Sci., 24, 1327 (1984).
20. C. D. Han and H. K. Chuang, J. Appl. Polym. Sci., 30, 4431 (1985).

21. C. D. Han, J. Appl. Polym. Sci., 35, 167 (1988).

22. E. R. Harrell and N. Nakajima, J. Appl. Polym. Sci., 29, 995 (1984).

23. C. D. Han, Y. W. Kim, and S. J. Chen, J. Appl. Polym. Sci., 19, 2831 (1975).

24. W. H. Jo, H. G. Kim, and S. H. Chae, Polym. J., 25, 1023 (1993). 